\title{
Airway Microbiota and Allergic Diseases: Clinical Implications
}

\author{
Eman M Fouda* \\ Department of Pediatrics, Ain Shams University, Egypt
}

Submission: February 20, 2017; Published: May 31, 2017

*Corresponding author: Eman M Fouda, Department of Pediatrics, Ain Shams University, Egypt, Email: foudaeman@gmail.com

\section{Introduction}

Bronchial Asthma is an airway disease with variable degrees of bronchial mucosal inflammation and intermittent episodes of airway obstruction and bronchial hyperesponsivness. That asthma is a syndrome consisting of different phenotypes has been recognized for a long time by clinicians [1]. New evidence indicates that the composition of airway microbiota differs in states of health and disease. Different chronic airway diseases had been related to changes in microbiota due to various factors which could affect severity of symptoms and even response to treatment [2]. Micro biome may be one of the protective factors against asthma in early life [3].

\section{What is Airway Microbiota}

It a complex variety of microbes present intrachea and different generations of the bronchi either on the mucus layer or the epithelial surfaces or even both. These microbes include bacteria, yeasts, viruses and bacteriophages. The bacterial part of microbiomeis the most prevalent component with various genera: Prevotella, Sphingomonas, Pseudomonas, Acinetobacter, Fusobacterium, Megasphaera, Veillonella, Staphylococcus, and Streptococcus. The bronchial tree for instance contains a mean of 2000 bacterial genomes per $\mathrm{cm}^{2}$ surface [4]. The mucosal surfaces in the human body are the home of 10-100 trillion microbes with a diversity of greater than 1,000 species [5]. The highest concentration of microbes is found in the GI tract, compared to those found in the lower airways. Healthy human lungs are not sterile, as previously believed, but it is unknown whether the microbes in the lungs form a stable community or are a series of transient colonizers [6].

However, various theories about the origin of lower airway microbiota in healthy individuals had been suggested. As it may represent true colonization of the lower generations of bronchi, or it is the result of turnover of the microbial community or it is just contamination of oropharynx during lower airway sampling or even linked potentially to those who are incorrectly categorized as truly healthy [7].

\section{Importance of microbiota}

The commensal bacteria are nonpathogenic and defend our airways against the pathogens. There are several possible mechanisms:

1. Commensals are the native competitors of pathogenic bacteria, because they occupy the same niche inside the human airways.

2. They are able to produce antibacterial substances called bacteriocins which inhibit the growth of pathogens. Genera Bacillus, Lactobacillus, Lactococcus, Staphylococcus, Streptococcus, and Streptomyces are the main producers of bacteriocins in respiratory tract.

3. Commensals are good inducers of anti allergic Th1 cascade with anti-inflammatory interleukin (IL)-10, FOXP3, and secretory immunoglobulin A (sIgA) production [7].

\section{Airway epithelial cell and microbiota interaction}

The airway epithelium together with alveolar macrophages and dendritic cells collectively can recognize of bacterial products trapped into the lower airways with the inhaled air. Some of these products are can potentiate pro inflammatory stimuli. So it is a challenging issue to distinguish between pathogens and commensals to avoid development of constant or persistent inflammation and help to develop tolerance against harmless microbiota [8].

Once pathogenicbacterium (e.g.,S. pneumoniae, P.aeruginosa) has been attached to activated pattern recognition receptors located on/in bronchial epithelial cells, the proinflammatory cytokines pathways are predominant via release of IL-1, IL-6 and IL-8 which induce neutrophils, dendritic cells and macrophages chemotaxis to target cells (e.g., neutrophils, dendritic cells and macrophages. Standard microbiota fail to induce strong signaling, thus aborting inflammation. (Figure 1) [9]. 


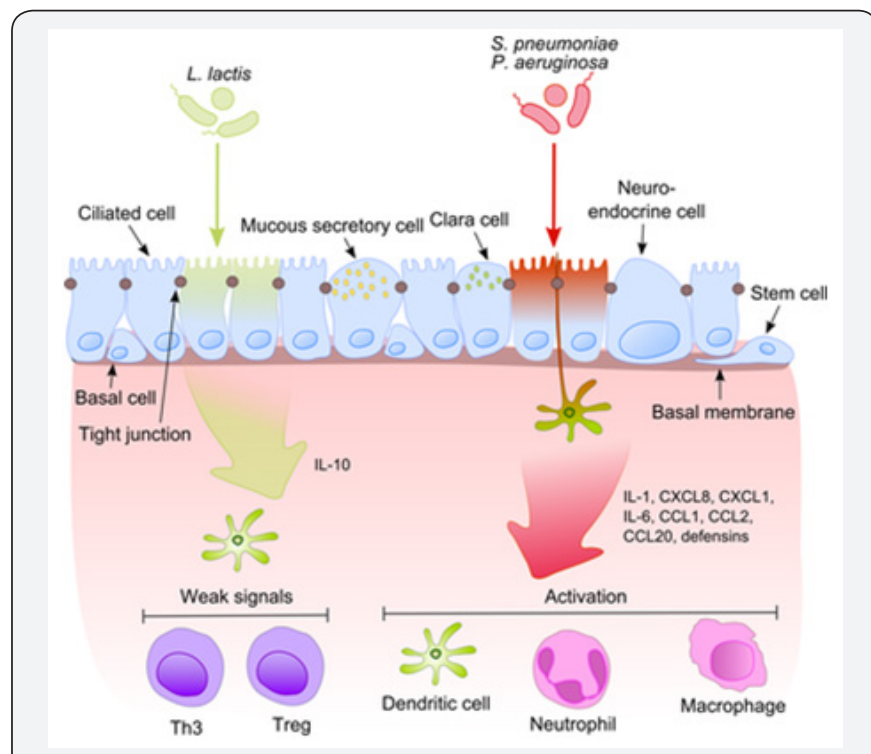

Figure 1: Mechanisms underlying the inflammation [9].

This process becomes much more intriguing when taking into account that commensals often share their surface molecules with pathogens. Epithelial cells are equipped with very sensitive recognition tools - toll like receptors (TLRs), NOD like receptors (NLRs) and retinoic acid-inducible gene (RIG)-I-like receptors (RLRs) which determine presence of non commensal bacteria which activate cellular components of the adaptive and innate immunity and recruit them to the infection site [7].

$N F-\kappa B$ is the principal regulators of different response to harmful microbiota as it is become activated by a number of stimuli as bacterial cell walls or inflammatory cytokines. This results in its translocation from the cytoplasm into the nucleus to activate epithelial cells pro-inflammatory genes. These specific genes can recognize a particular nucleotide sequence (5'-GGG ACT TTC T-3') in upstream region of response genes. [10]. Inspite of expressing express the same microbe-associated molecular patterns (MAMPs), harmless bacteria fails to translocate NF- $\kappa \mathrm{B}$ into the nucleus thus preventing the inflammation. The balance between pathogens and commensals is extremely important in the maintenance of homeostasis in the respiratory tract [9].

\section{Pediatric acterial airway microbiota in early life}

A neonatal mouse exposed to a broad-spectrum antibiotic has been shown to increase allergen-induced airway inflammation susceptibility [4]. Germ-free mice also exhibit enhanced airway inflammation upon allergen exposure [3], while colonizing OF germ free mice with microbiota from conventional mice decreased accumulation of natural killer T (NKT) cells in their airways .This was only observed in neonates not in adult mice. This highlights the importance of early life as a critical period for intervention [11].

Absence of airway colonization during this critical neonatal window resulted in sustained susceptibility to allergic inflammation through adulthood. This ensure long-term control of allergic airway inflammation via controlling commensal bacteria communities early in early life [12].

\section{Microbiota and climax community}

Climax community is defined as a microbial community that has reached a final or "climax" steady state best adapted for growth at that specific niche along the mucosa. However, this climax community is dynamic and still exhibits both resistance and resilience [13]. Evidence is now accumulating that longterm dietary pressures, repeated antibiotic use, GI illnesses or medications such as antacids, proton pump inhibitors, and nonsteroidal anti-inflammatory drugs can break both the resistance and resilience of a community and result in it re-assembling into another climax community, although this may be accompanied by detrimental changes in host mucosal immuno biology and physiology. One mechanism underlying the activity of probiotic microbes and prebiotic nutrients may be the ability to restructure a climax community to improve host mucosal immuno biology and physiology [14].

\section{Microbiota (microflora) hypothesis}

Several theories had been suggested to explain the increase in the incidence of asthma and other allergic diseases over the past 30 years and the discrepancy between the higher rates of allergic disease among industrialized relative to developing countries. One rising assumption is a lack of early microbial stimulation which results in aberrant immune responses to innocuous antigens later in life "hygiene hypothesis" [15]. Life style modifications and over use of broad spectrum antibiotics raise the concept of disturbance of mechanisms of mucosal immunologic tolerance due to changing diversity of gastrointestinal (GI) microbiota composition in westernized areas [16].

\section{Epidemiologic and clinical data supporting this interpretation include}

a) a positive correlation between increasing risk for asthma/allergies and increasing use antibiotics in industrialized countries,

b) Altered fecal microbiota composition had been correlated to different atopic diseases

c) Oral probiotics orsignificant dietary changes lead to some successful prevention/reduction of severity of allergic diseases.

Experimental data in mice compared that immune response generation and normal ones which showed numerous defects in immune response [17]. Altogether, these experimental, epidemiologic, and clinical observations support the hypothesis that even minor changes in the quality or quantity of airway microbiota can be one of the predisposing factors for allergic disease [10]. 


\section{Cross-talk between the gut and the lung}

The existence of the gut-lung axis and its implications for airway disease provide a portal for potential therapeutic intervention in prevention or management of asthma [18]. Oral supplementation with probiotic strain of Bifidobacterium and prebiotic non-digestible oligosaccharides reduced airway IL6 and IL4 levels and protected against HDM-induced airway inflammation. This suggest that some intestinal bacteria have the capacity to suppress inflammation at a distal mucosal site [19].

\section{Oral tolerance and airway tolerance}

Oral tolerance is defined as the propensity of ingested antigens to abort subsequent systemic immune responses. Gastrointestinal tract may be also involved in tolerance to inhaled and ingested antigensvia CD4+ regulatory T cells (Tregs) that produce immunosuppressive cytokines, IL-10 and TGF $\beta$, in what is termed "bystander suppression." [19,20]. Mucosal signals, such as those from the microbiota, keep resident dendritic cells in an immature or non-inflammatory state [15].

\section{Airway microbiata diversity in asthma}

In asthmatic patients, certain airway microbial composition was associated with airway eosinophilia and AHR to mannitol but not airway neutrophilia. Comparing eosinophilic and noneosinophilic asthmaas regards airway microbiome revealed that Asthmatic patients with the lowest levels of eosinophils had an altered bacterial microbial profile, with more Neisseria, Bacteroides, and Rothia species and less Sphingomonas, Halomonas, and Aeribacillus species compared with asthmatic patients with high eosinophilia. This may invite furtherresearch on effect of modulating diversity of microbiota to modulate various asthma phenotypes [21].

\section{Airway microbiota dysbiosis in asthma}

Airway dysbiosis in patients with severe asthma appears to differ from that observed in those with milder asthma. Specific Bacterial communities as Proteobacteria were associated with worsening ACQ scores and sputum total leukocyte values in severe and poorly controlled asthma. Actinobacteria had been associated with stable or even improving ACQ scores and can predict steroid responsiveness [22].

\section{Airway microbiota and asthma heterogeneity}

Dissecting the role of the microbiome in asthma is challenged by the heterogeneity of the disease at multiple levels (Figure 2). These levels include asthma's clinical and inflammatory heterogeneity, genetic factors that contribute to asthma risk, and the multiplicity of immune pathways involved in asthma. The potential effects of environmental exposures on gene function, immune responses, as well as microbiota composition add further complexity. As with genetics, mechanistic consequences of the altered microbiome may explain certain aspects or phenotypes of asthma as the development of allergic or non-allergic asthma, and treatment-resistant asthma) [22] Components of the depicted system-host genetics and immunology, microbiota, environmental exposures, and the disease of asthma- are themselves heterogeneous entities, presenting challenges to more precisely dissect the role(s) of the microbiome in asthma.

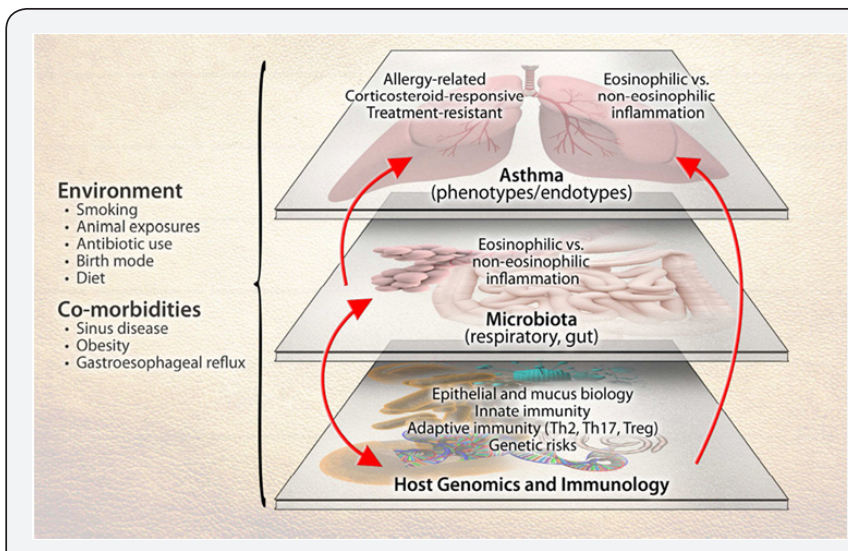

Figure 2: The interface of microbiota interactions with other factors that collectively can influence susceptibility to asthma or its manifestations.

\section{Upper airway microbiota and asthma}

Bisgaard et al. [23] demonstrated that the nasopharyngeal microbiome composition was influenced by the early life exposures, including attending day care, having siblings, and taking antibiotics. Haemophilus, Streptococcus, Moraxella had been previously associated with airway disease and increased risk for asthma exacerbations. Early colonization with either Moraxella, or Streptococcus was strongly associated with acute lower respiratory viral infections. This colonization can be predictor for asthma development later in life.

Thus, probiotic intervention studies of animals provide encouraging evidence for intentional manipulation of the intestinal microbiota as a strategy for asthma prevention and management. A meta-analysis of a large number of randomized trials of probiotic supplementation, on atopic sensitization and asthma in children, however, shows that the success of these interventions in mice does not translate easily to disease prevention in humans. At a minimum, this highlights that different probiotics may have distinct interactions with the host microbiome and that some strains might be more specific for modulating atopic inflammation but many other considerations, such as diet, age of intervention, coincident environmental exposures, length of supplementation period, and other as yet unknown factors, are likely important [24].

\section{Airway microbiota and severity of asthma}

Relationships between the airway microbiome and disease features have also been examined in patients with in severe asthma. Different clinical phenotypes of severe asthma have been described, suggesting the possible involvement of alternate mechanistic pathways, as has been surmised for asthma in 
general. A preliminary analysis of the bronchial microbiome in these subjects, poorly controlled despite high-dose ICS therapy, noted significant relationships between different bacterial community profiles and features such as body-mass index and measures of asthma control [25]. A similar study of sputum bacterial composition in 28 treatment-resistant asthmatics found that the relative abundance of M. catarrhalis, Haemophilus, or Streptococcus spp. correlated with worse lung function and higher sputum neutrophil counts and IL-8 concentrations [19].

\section{Microbiota and therapy of allergic disease}

The composition of the microbiota can be manipulated by combinations of antibiotics, probiotics, and dietary components which may have direct growth promoting or inhibiting activity for specific microbes. [26]. Certain types of fatty acids, phenolic compounds, and carbohydrates may modulate these microbiota. However, a single type of probiotic or dietary component will not be efficacious in all individuals. This likely due to differences in the types of microbial communities in different individuals. The objective of the international Human Microbiome Project is to characterize and define the human microbiome in states of health and disease [10]. The challenge for future research is to use this information to optimize probiotic/dietary therapy to improve human health and prevent microbiota-associated diseases, such as allergies.They are likely to include short chain fatty acids and ionic polysaccharides [27] .

\section{Microbiota and prevention of allergic disease}

Probiotic intervention studies of animals provide encouraging evidence for intentional manipulation of the intestinal microbiota as a strategy for asthma prevention and management. However, A large number of randomized trials on the value of probiotic supplementation, on asthma incidence and severity in children, could not show the same success of these interventions as in mice [28-30]. This may be due to many other considerations, such as diet, age of intervention, coincident environmental exposures, length of supplementation period, and other as yet unknown factors, are likely important $[24,31$ 34].

\section{References}

1. Chung KF (2014) Defining phenotypes in asthma: a step towards personalized medicine. Drugs 74(7): 719-728.

2. Wade WG (2013) The oral microbiome in health and disease. Pharmacol Res 69(1): 137-143.

3. Herbst T, Sichelstiel A, Schär C, Yadava K, Bürki K, et al. (2011) Dysregulation of allergic airway inflammation in the absence of microbial colonization. Am J Respir Crit Care Med 184(2): 198-205.

4. Russell SL, Gold MJ, Hartmann M, Willing BP, Thorson L, et al. (2012) Early life antibiotic-driven changes in microbiota enhance susceptibility to allergic asthma. EMBO Rep 13(5): 440-447.

5. O'Hara AM, Shanahan F (2006) The gut flora as a forgotten organ. EMBO Rep 7(7): 688-693.

6. Hilty M, Burke C, Pedro H, Cardenas P, Bush A, et al. (2010) Disordered microbial communities in asthmatic airways. PLoS One 5(1): e8578.
7. Huang YJ, Lynch SV (2011) The emerging relationship between the airway microbiota and chronic respiratory disease: clinical implications. Expert Rev Respir Med 5(6): 809-821.

8. Beck JM, Young VB, Huffnagle GB (2012) The microbiome of the lung. Transl Res 160(4): 258-266.

9. Kumar Himanshu, Kawai, Taro, Akira Shizuo (2011) "Pathogen Recognition by the Innate Immune System". Int Rev Immunol 30 (1): 16-34.

10. Turnbaugh PJ, Ley RE, Hamady M, Fraser-Liggett CM, Knight R, et al. (2007) The human microbiome project. Nature 449: 804-810.

11. Olszak T, An D, Zeissig S, Vera MP, Richter J, et al. (2012) Microbial exposure during early life has persistent effects on natural killer. Science 336(6080): 489-493.

12. Gollwitzer ES, Saglani S, Trompette A, Yadava K, Sherburn R, et al. (2014) Lung microbiota promotes tolerance to allergens in neonates via PD-L1. Nat Med 20(6): 642-647.

13. Allison SD, Martiny JB (2008) Colloquium paper: resistance, resilience, and redundancy in microbial communities. Proc Natl Acad Sci 105(Suppl 1): 11512-11519.

14. Dethlefsen L, Huse S, Sogin ML, Relman DA (2008) The pervasive effects of an antibiotic on the human gut microbiota, as revealed by deep 16S rRNA sequencing. PLoS Bio 6(11): e280.

15. Belkaid Y (2007) Regulatory $T$ cells and infection: a dangerous necessity. Nat Rev Immunol 7: 875-888.

16. Noverr MC, Huffnagle GB (2005) The 'microflora hypothesis' of allergic diseases. Clin Exp Allergy 35(12): 1511-1520.

17. Larsen JM, Steen-Jensen DB, LaursenJM, SøndergaardJN, Musavian HS et al. (2012) Divergent pro-inflammatory profile of human dendritic cells in response to commensal and pathogenic bacteria associated with the airway microbiota. PLoS One 7(2): e31976.

18. Verheijden KA, Willemsen LE, Braber S, Leusink-Muis T, Jeurink PV, et al. (2016) The development of allergic inflammation in a murine house dust mite asthma model is suppressed by synbiotic mixtures of nondigestible oligosaccharides and Bifidobacteriumbreve M-16V. Eur J Nutr 55(3): 1141-1151.

19. Green BJ, Wiriyachaiporn S, Grainge C, Rogers GB, Kehagia V, et al. (2014) Potentially pathogenic airway bacteria and neutrophilic inflammation in treatment resistant severe asthma. PLoS One 9(6): e100645.

20. Mowat AM (2003) Anatomical basis of tolerance and immunity to intestinal antigens. Nat Rev Immunol 3(4): 331-341.

21. Sverrild A, Kiilerich P, Brejnrod A, Pedersen R, Porsbjerg C, et al. (2016) Eosinophilic airway inflammation in asthmatic patients is associated with an altered airway microbiome. J Allergy ClinImmunol. S00916749(16): 32475-32477.

22. Huang YJ, Nariya S, Harris JM, Lynch SV, Choy DF, et al. (2015) The airway microbiome in patients with severe asthma: Associations with disease features and severity. J Allergy Clin Immuno 136(4): 874-84.

23. Teo SM, Mok D, Pham K, Kusel M, Serralha M, et al. (2015) The infant nasopharyngeal microbiome impacts severity of lower respiratory infection and risk of asthma development. Cell Host Microbe. 17(5): 704-715.

24. Elazab N, Mendy A, Gasana J, Vieira ER, Quizon A, et al. (2013) Probiotic administration in early life, atopy, and asthma: a meta-analysis of clinical trials. Pediatrics 132(3): e666-76.

25. Wu W, Bleecker E, Moore W, Busse WW, Castro M, et al. (2014) Unsupervised phenotyping of Severe Asthma Research Program participants using expanded lung data. J Allergy Clin Immunol 133(5): 1280-1288. 
26. Borchers AT, Selmi C, Meyers FJ, Keen CL, Gershwin ME (2009) Probiotics and immunity. J Gastroenterol 44: 26-46.

27. Mazmanian SK, Round JL, Kasper DL (2008) A microbial symbiosis factor prevents intestinal inflammatory disease. Nature 453: 620-625.

28. Antonopoulos DA, Huse SM, Morrison HG, Schmidt TM, Sogin ML, et al. (2009) Reproducible Community Dynamics of the Gastrointestinal Microbiota Following Antibiotic Perturbation. Infect Immun.77(6) 2367-2375

29. Bisgaard H, Hermansen MN, Buchvald F, Loland L, Halkjaer LB, et al (2007) Childhood asthma after bacterial colonization of the airway in neonates. N Engl J Med 357(15): 1487-1495.

30. Blaser MJ (2006) Who are we? Indigenous microbes and the ecology of human diseases. EMBO Rep 7(10): 956-960.
31. Ege MJ, Mayer M, Normand AC, Genuneit J, Cookson WO, et al. Exposure to environmental microorganisms and childhood asthma. N Engl J Med 364: 701-709.

32. Fujimura KE, Demoor T, Rauch M, Faruqi AA, Jang S, et al. (2014) House dust exposure mediates gut microbiomeLactobacillus enrichment and airway immune defense against allergens and virus infection. Proc Natl Acad Sci 111(2): 805-810.

33. Huang YJ, Boushey HA The microbiome in asthma. J Allergy Clin Immunol 135(1): 25-30.

34. Specjalski K, Jassem E (2011) Chlamydophilapneumoniae, Mycoplasma pneumoniae infections, and asthma control. Allergy Asthma Proc 32(2): 9-17.

Your next submission with Juniper Publishers will reach you the below assets

- Quality Editorial service

- Swift Peer Review

- Reprints availability

- E-prints Service

- Manuscript Podcast for convenient understanding

- Global attainment for your research

- Manuscript accessibility in different formats (Pdf, E-pub, Full Text, Audio)

- Unceasing customer service

Track the below URL for one-step submission https://juniperpublishers.com/online-submission.php 